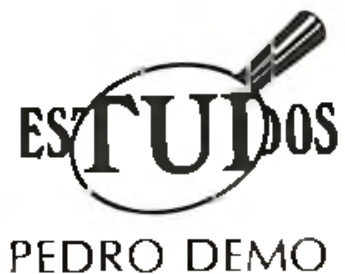

\title{
A burocracia não resiste a uma sociedade bem organizada
}

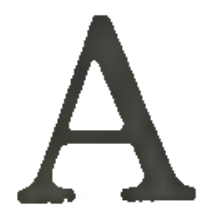

ntes, desburocratizar sienificava princlpal mente o esforço do Es tado voltado para si mesmo. Era o compromisso em recuperar sua próprla dignidade. dlante do cidac ão Impotente. Significava simpliticar a vida das pessoas, reduzir papéis Inúteis, abrir o caminho ao serviço público.

Nāo se pode negar que tudo Isto ocupou espaco importante na vida do pals, até porque se teve a feliz idéia de colocar a tarefa num Mlnistério Extraordinário - porquanto uma burocracia ordinária nāo terla condiçōes de demover a ordinariedade da burocracia.

Hoje, desburocratizar adquire outra significaçāo, adequada ao tempo da democracia. Descobrimos logo que o Estado nāo pode ser seu avalista, já que costuma enganar a cidadāo. É multo limltada a pretensāo de o Estado desburocratizar-se a si mesmo. Sua dignldade nāo está propriamente nele, mas no cidadăo organlzado. Desburocratizar é muito mals uma conquista da socledade, à medida que se organiza, do que boa vontade do Estado.

Ao mesmo tempo, constata-se facilmente que a promoçāo da capacidade Individual de reclamar nāo é a melhor Idéla, ainda que intrinsecamente válida, porque é direito Indlvidual também. A melhor idéla é motivar a organlzaçāo do cidadāo em torno de seus legitimos interesses, para que ele mesmo, onde está, arrume um caminho de soluçāo, no sentido de saber dirlglr-se ao lugar certo e exercer sua pressāo potenclada.

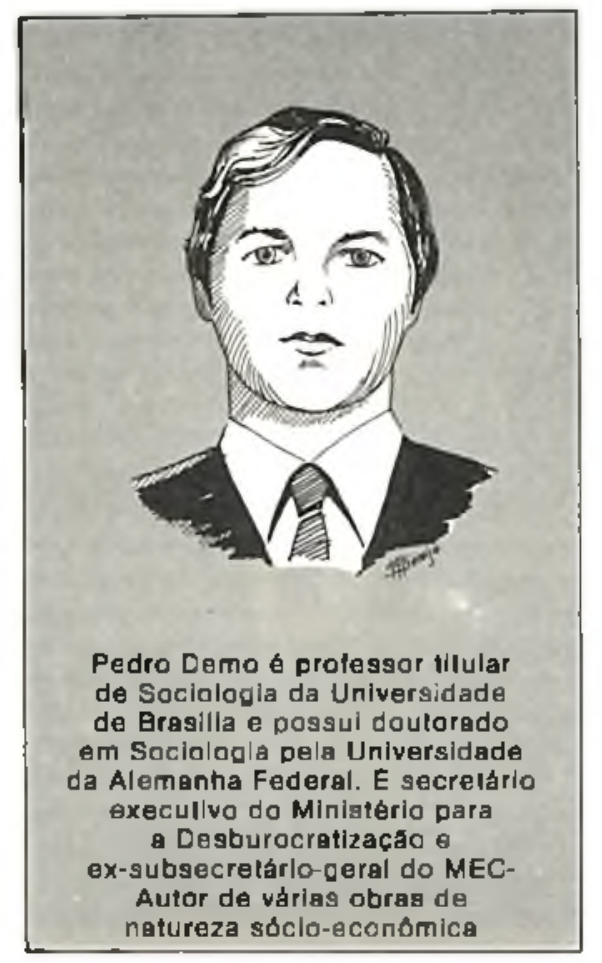

A reclamaçāo indivldual velculada à burocracla estatal pode sofrer a llusão de tratamento especial. mas está sempre muito longe de qualquer soluçāo, porque está de novo entregue aos cuidados buracrátlcos. No fundo, emerge um componente compensatório típico das politicas sociais que tratam bem do carente, mas nāo se comprometem com qualquer soluçáo.

A partir dessa visāo, desburocratizar começou a mudar o rumo em direçāo ao espaço da cldadanla. Se - problema é controlar o Estado. vigiar os serviços públicos, respejtar os direltos clvis - e como decorrêncla desburocratlzar -, o jogo se resolve em outra arena, que é o plano do exerciclo da cldadania. E menos uma questăo de adminls-
Iracâo, do que de desenvolvimento politico.

O Intortúnlo de nossa burocracia. em grande parte inútil, perdulária. perversa, advém principalmente de nossa pobreza polltica. Faz parte da característica de massa de manobra, que acomete grande parte da populaçáo. Sujeita-se aos descalabros do serviço público e chega a tomá-los por normals, ao ponto de se assustar, quando encontra algo que funcione bem. Inverte seus direltos, e acha que recebe favor. Nāo reage dlante do abuso do poder estatal e do poder econômico.

Trata-se, pols, de uma questáo estrutural, dư nāo se resolve com medidas intermitentes de simpliflcaçāo cartorlal. Sem organizaçāo democrática da socledade, nāo floresce o tecido associativo capaz de resistir aos impetos do autoritarismo: nāo amadurece a noçāo de direltos clvis: nāo emerge a necessidade hlstárica de conqulstar espaço próprio: nāo se coagula a fé de um povo em suas potencialidades; nāo se arma a identldade cultural necessáría à motlvaçāo partlclelpativa: náo se garantem os passos da autodeterminaçāo.

A burocratlzaçāo faz força na direçāo da desmobilizaçăo socia], porque foge da critlca e sobretudo da autocritica. Prefere o analfabeto e o despreparado, porque pode ma nipular mals facllmente. Aprecla a centralizaçāo, porque mascara na conjuntura de uma pretensa eficiēncla a estrutura dos privilégios.

Faz sentido montar no Estado órgăos de defesa do consumidor. Mas existe af um risco sempre iminente. Enquanto o Estado promete a 
defesa, sobretudo se autodefende Por isso facilmente prollfera ins tâncias, que têm por finalidade muito mals adornar e ccnsolidar a lecnocracla, do que resolver problemas do consumidor lesado. Este reclama e náo é atendido de rato. ainda que possa receber uma carta delicada, onde se diz que o Estado reconhece o direito do cldadāo, que se lamenta o ocorrido, e que já se encaminhou aos canals competen tes.

O que Iaz sentido mesmo, no en Lanto, é motivar o consumidor a organizar-se por sí, procurando no Estado simples apoio, por vezes as sessoria. Com isto aprende na prá Llica 0 que fazer, e sobretudo que nāo pode entregar-se nas māos do Estado. Constról sua estratégia de como enfrentar a situacão, desde açōes legais, pressōes sobre autoridades competentes, denúnclas pú blicas, até iniciativas proprlas de controle da qualidade dos bens $e$ serviços.

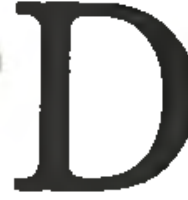

faz com eventos,

emergências intermitentes, com zrroubos espasmódicos,

mas com a formacão qualitativa da cidadania, que amadurece na capacldade historica de conquista de autodeterminaçāo. Se for assim, a conseqüêncla é a desburocrattzaçào

Desburocratıar não é, assım, tarefa propriamente administrativa $e$ juridica, mas sobretudo politica. que passa necessariamente pela conquista por parte do desigual do direito à mesma oportunidade. E questão de colocar o Estado sob tal pressăo da sociedade clvll, que se sinta a cada momento viglado e obrigado a um minimo de dignida- de. E questăo precisamente de cidadanla.

Neste sentldo, precisamos invest/r num processo politico de extensảo e intensidade geracional, que passa inevitavelmente pela educacão, pela informaçăo, pela participaçáo. Resultados imediatos sāo sempre menos profundos que a construçáo estrutural do lastro organizado de um povo, para que nāo seja apenas um bando de gente. entregue às vicissitudes da prepotêncla estatal e econỏmlca. Democra cia náo se laz com eventos. com emergências Intermitentes. com ar roubos espasmódicos, mas com a formaçāo qualitativa da cldadania que amadurece na capacidade histórica de conquista da autodetermi naçāo

Se assim for, desburocratizar é consequiêncla. Onde há o cídadāo autêntico, consciente e organizado - Estado se obriga a desburo cratizar-se.

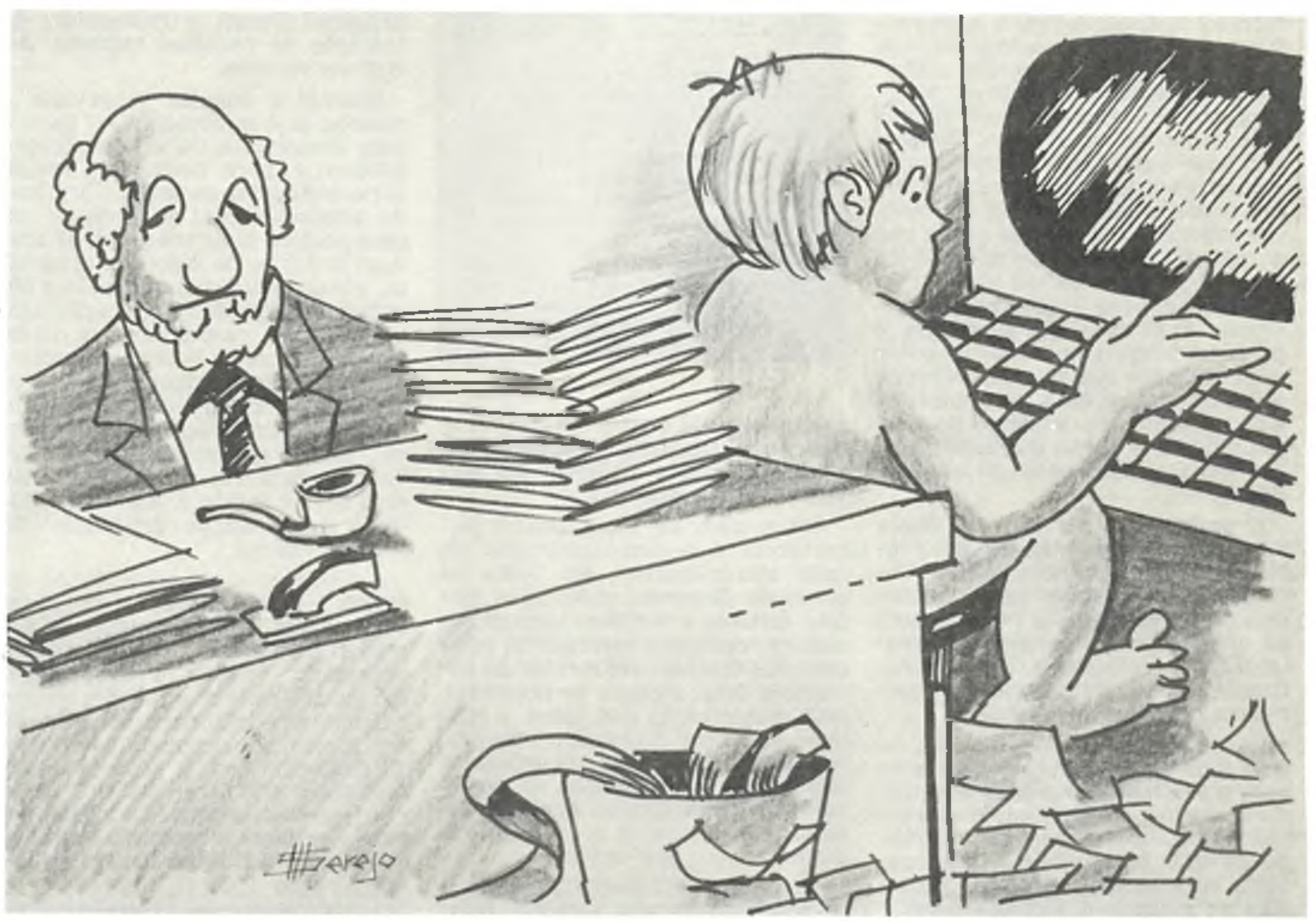

